\section{Achieving successful ileal intubation during retro- grade double balloon enteroscopy: description of a novel, alternative technique (with video)}

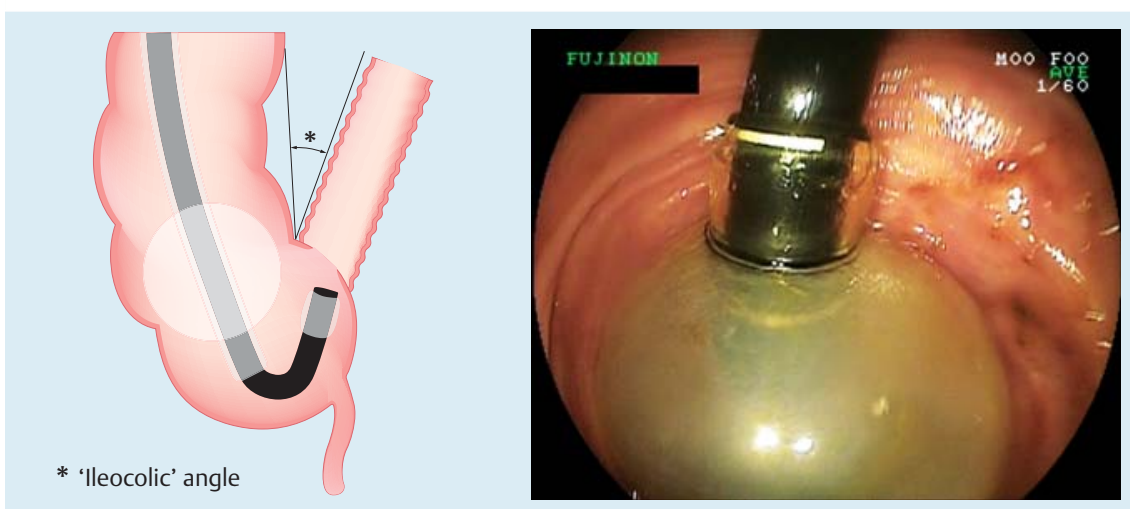

Fig. 1 Retroflexion of the enteroscope in the cecum with the overtube balloon inflated to stabilize the position of the enteroscope.

In double-balloon enteroscopy (DBE), the retrograde approach is considered technically more challenging, with published failure rates for ileal intubation as high as $30 \%$ [1]. The technique for ileal intubation described by Yamamoto et al. involves visualizing the ileocecal valve (ICV) while the overtube balloon is inflated in the ascending colon, followed by pull-back of the balloon to reduce the ileocolic angle (thus exposing the ICV) and then intubation of the ileum with the enteroscope, all in the forward view [2]. In our experience, and as evidenced by other published series, ileal intubation can still fail despite this maneuver $[1,3]$.

We describe an alternative method for ileal intubation when the standard technique is unsuccessful. This is particularly useful when the ileocolic angle cannot be reduced sufficiently by pull-back of the overtube balloon in the usual fashion or when the ICV is very backward facing.

Step 1: Both the enteroscope and the overtube are passed into the cecum, the overtube balloon is inflated, and the ICV is visualized by the enteroscope in the retroflexed view; the enteroscope balloon remains deflated ( $\bullet$ Fig. 1, $\bullet$ Video 1 ).

\section{Video 1}

Demontration of the alternative technique of ileal intubation at retrograde double-balloon enteroscopy.

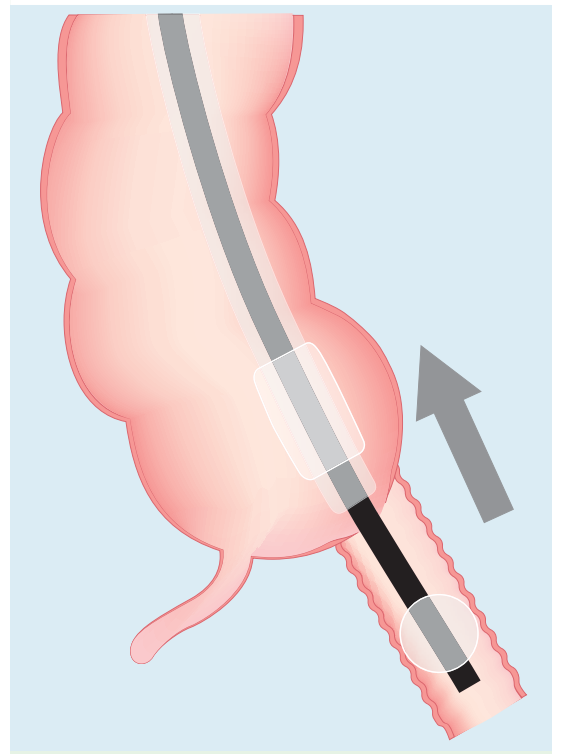

Fig. 3 With the enteroscope balloon inflated in the terminal ileum, the enteroscope and overtube are pulled back to straighten the ileocolic angle.

Step 2: The enteroscope is advanced into the terminal ileum while in the retroflexed position. The enteroscope balloon is then inflated, allowing the enteroscope balloon to grip the terminal ileum in preparation for step 3 ( $\bullet$ Fig. 2 ).

Step 3: While the enteroscope balloon is inflated in the terminal ileum, the overtube balloon is deflated and the enteroscope and overtube are pulled back together, straightening the enteroscope in

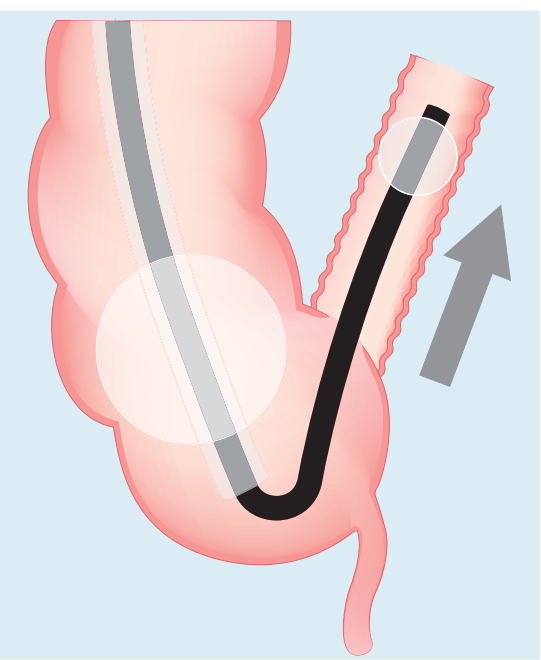

Fig. 2 The enteroscope is advanced into the terminal ileum; the enteroscope balloon is then inflated.

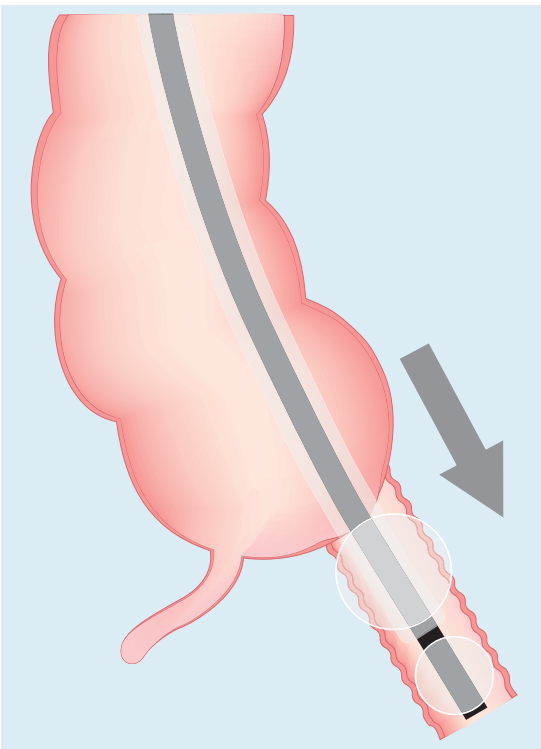

Fig. 4 The overtube is advanced into the terminal ileum; the overtube balloon is then inflated.

preparation for advancement of the overtube into the terminal ileum ( $\bullet$ Fig. 3 ).

Step 4: The overtube is advanced across the ICV into the terminal ileum and the overtube balloon is inflated ( Fig. 4).

Step 5: With the enteroscope balloon deflated, the enteroscope is advanced deeper into the ileum while the overtube balloon remains inflated. The DBE insertion cycle [2] can then be resumed ( $\bullet$ Fig. 5 ).

Endoscopy_UCTN_Code_TTT_1AP_2AD 

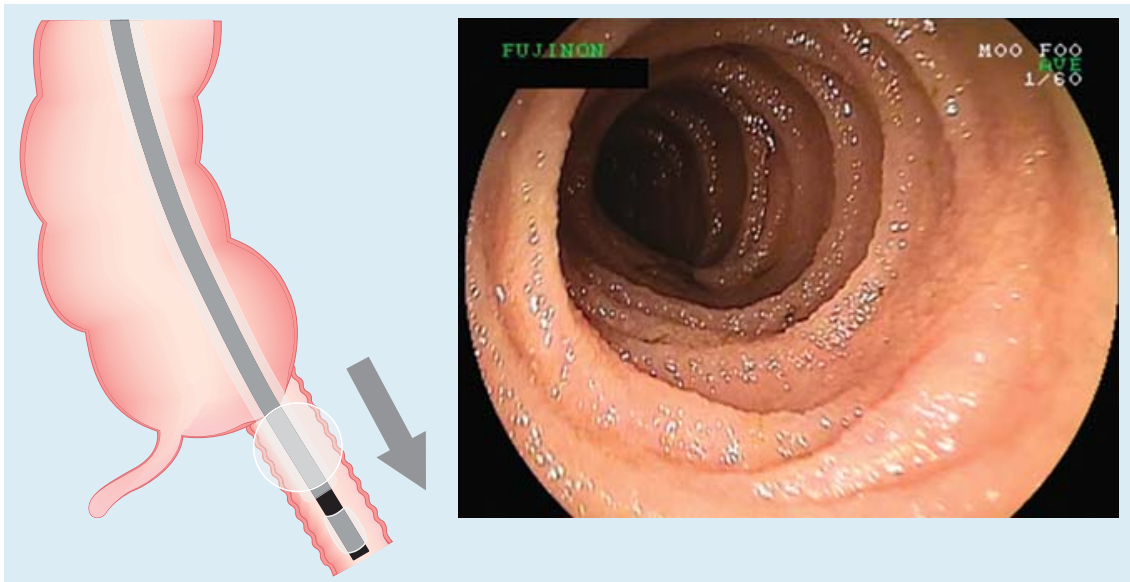

Fig. 5 The enteroscope balloon is deflated and the enteroscope is advanced deeper into the ileum allowing the DBE insertion cycle to resume.

Competing interests: A research grant was received from Fujinon/Endoscopy UK.

\section{E. Despott, C. Fraser}

The Wolfson Unit for Endoscopy,

St Mark's Hospital and Academic Institute, Imperial College, London, UK
2 Sugano K, Yamamoto H, Kita H. Double-balloon endoscopy: theory and practice. Tokyo: Springer, 2006

3 Mehdizadeh S, Han NJ, Cheng DW et al. Success rate of retrograde double-balloon enteroscopy. Gastrointest Endosc 2007; 65: 633-639

Bibliography

DOI $10.1055 / \mathrm{s}-0029-1215283$

Endoscopy 2009; 41: E309-E310

(c) Georg Thieme Verlag KG Stuttgart · New York . ISSN 0013-726X

Corresponding author

\section{Fraser, MD}

The Wolfson Unit for Endoscopy

St Mark's Hospital and Academic Institute Imperial College

Watford Road

London

HA1 3UJ

UK

chris.fraser@imperial.ac.uk 